\title{
COMPARATIVE STUDY OF THE EFFECT OF LASER IRRADIATION AND ACID ETCHING SURFACE TREATMENT ON BONDING OF SOME DENTAL RESTORATIVE MATERIALS TO DENTIN SURFACE
}

\author{
Tarek Abdel-Hamid Harhash*
}

\begin{abstract}
This study was carried out to evaluate the effect of acid etching versus laser etching of dentin surface on the bonding of Composite and Compomer restorative materials to dentin surface by studying microleakage at the dentin-filling interface, compositional analysis of dentin surface, and Scanning Electron Microscopic (SEM) study of the bonding area. 120 freshly extracted premolar teeth were divided according to surface treatment into three groups. Group I (Acid etching group) contained thirty teeth. Twenty teeth were selected to assess microleakage by forming standardized class V cavity on the buccal surface of the selected teeth. Then, teeth were subdivided into two subgroups with 10 teeth in each. Subgroup (i) delivered composite filling while subgroup (ii) delivered compomer filling according to manufacturer instructions. microleakage at the dentinfilling interface of teeth was examined using dye penetration method. dye penetration scores at occlusal and gingival margins were recorded and tabulated. Five dentin surfaces of five teeth from group I were etched by acid then prepared for compositional analysis of dentin surface by Infra-Red (IR) Spectroscopy. Another Five dentin surfaces were etched by acid then prepared for (SEM) assessment. Group II (Laser etching group) contained ninety teeth, twenty teeth were used for assessing microleakage after laser etching taking similar steps to that of acid etching. Thirty dentin surfaces of thirty teeth were etched by laser with different parameters then prepared for compositional analysis of dentin surface by IR Spectroscopy. Thirty dentin surfaces of thirty teeth were etched by laser with different parameters then prepared for SEM assessment. Group III (Untreated group) contained ten teeth that were left untreated. Five dentin surfaces of five teeth were subjected to IR Spectroscopy assessment. Five dentin surfaces of five teeth were prepared for SEM assessment. The results revealed that acid etching of dentin surface resulted in significant less leakage compared to laser etching. IR Spectroscopy revealed changes in dentin surface structure indicating that there was a reaction occurred by the acid and laser etching. SEM assessment showed more openings of dentinal tubules in case of acid etching, while in case of laser etching, there were a surface structural changes with a melting and fusion dentin surface. Acid etching of dentin gives better results on the bonding of Composite and Compomer filling materials than laser etching and thus gives more successful clinical condition. Further investigations are needed by using different types of laser to get more benefit from applications of laser clinically.
\end{abstract}

KEYWORDS: Laser, Microleakage, IR spectroscopy, SEM, Dentin etching.

* Asst. Professor of Laser Dental Applications, Department of Medical applications of Laser, National Institute for Laser Enhancement Sciences, Cairo University. 


\section{INTRODUCTION}

The treatment of dental tissues prior to adhesive restorative procedures is an extremely important step in the bonding protocol and determines the clinical success of restorations. Dentin is a complex structure which can influence the bonding of restorative systems; therefore, bonding to dentin surface is a greater challenge than to enamel surface ${ }^{(1)}$. Considering bonding to dentin, a combination of both micromechanical and chemical bonding was likely to occur. The bond between dentin and composite is more micromechanical than chemical ${ }^{(2)}$.

Preparation with rotating instruments produces a smear layer which contains hard particles, blood, bacteria and saliva ${ }^{(3)}$. Acid etching dissolves the smear layer, demineralize the peritubular and intertubular dentin and exposes the collagen matrix ${ }^{(2)}$.

The demineralized dentin is infiltrated by resin monomers which create a hybrid layer after their polymerization ${ }^{(4)}$. To create the hybrid layer, it is necessary to remove the smear layer and demineralize the superficial dentin layer. Etching exposes the collagen fiber network of the dentin matrix, thereby permitting infiltration of bonding agents into the spaces between the fibers ${ }^{(2)}$. The fibers are engulfed and the complex fiber-resin is polymerized providing improved micromechanical retention of resin polymers ${ }^{(5)}$.

Sandblasting, acid etching and laser are methods used for enamel and dentin surface etching. However, some studies suggest that laser etching may produce bonding forces comparable to that produced by acid etching ${ }^{(6-8)}$, while others found that lower bonding forces were produced by laser when used for enamel surface etching ${ }^{(9-11)} \cdot \mathrm{CO}_{2}$ laser had many applications in dentistry that might differ according to its wavelength bands. The three main $\mathrm{CO}_{2}$ laser wavelengths used in dental treatments are 9300,9600 , and $10600 \mathrm{~nm}$. with a variety of hard and soft tissue effects, ${ }^{(12,13)}$ Bond strength with different laser treatments is not consistent either. Some studies have suggested that there was significant decrease in shear bond strength with laser etching ${ }^{14,15)}$, while others concluded that laser etching can produce comparable results to those produced by conventional etching ${ }^{(16-18)}$.

Consequently, this work was undertaken to evaluate the effect of acid etching and $\mathrm{CO}_{2}$ laser etching procedures of dentin on the Microleakage between dental restorative materials and the teeth surface.

\section{MATERIAL AND METHODS}

One hundred and twenty freshly extracted sound human permanent premolars teeth extracted for orthodontic purpose were selected and stored in distilled water after removing any adherent calculus, blood, stains, debris and periodontal shreds by scaling with sharp scalers, then polished with rotary hair brush and a mix of pumice and water.

The teeth were examined under light microscope for any surface morphological defects such as enamel fracture, cracks, restoration or carious lesions. Teeth with such defects were excluded from the study.

The teeth were divided into three groups according to the type of surface treatment, Group I (Acid etching group), Group II (Laser etching group), and Group III (Untreated Control Group).

\section{Group I (Acid etching group)}

This group contained thirty teeth. Twenty teeth were selected for assessment of microleakage in which a standardized rectangular class $\mathrm{V}$ cavity preparation (a mesio-distal width of $3 \mathrm{~mm}$, an occluso-gingival length of $2 \mathrm{~mm}$, and a depth of $2 \mathrm{~mm}$ ) was prepared on the buccal surface of each selected premolar with a gingival border of the cavity approximately $1 \mathrm{~mm}$ above the cementoenamel junction.

The outline of the cavity was standardized using a window like cut to the desired cavity measurements in a metallic matrix band. The precut matrix was held over the surface of the tooth and marked 
with a sharp pencil on the buccal surface of the selected premolars teeth. The preparations were cut using a new cylindrical crosscut tungsten carbide burs revolving at high speed using oil free air with air/water spray coolant system. The depth of the cavity was kept constant at $2 \mathrm{~mm}$ axially by using a pre-marked cylindrical bur and judged by using pre-marked calibrated periodontal probe. The performed cavities were rinsed for 20 seconds using air/water spray and gently dried with oil free compressed air for 30 seconds.

The teeth were then, subdivided equally into two subgroups according to the type of restorative filling materials into:

(a) Ten teeth were restored with composite filling material.

(b) Ten teeth were restored with compomer filling material.

For Composite restoration: $3 \mathrm{M}$ Scotchbond (3M Center, St. Paul, MN 55144-1000) etchant material was applied according to the manufacture instructions, the cleaned cavity preparation was etched with the $35 \%$ phosphoric acid gel for 15 seconds, then the surface was thoroughly rinsed with water for another 10 seconds and air dried with oil free air. 3M Single Bond dental adhesive system was then applied according to the manufacture instructions as follow:

The adhesive was applied to the etchant area using a fully saturated brush tip for each coat. Two consecutive coats were applied, dried gently for 2-5 seconds and then light cured with light cure unit (Kulzer GmbH, Leipziger Straße 2, 63450 Hanau) for 10 seconds.

3M Filtek Z250 (3M Center, St. Paul, MN 55144-1000) restorative composite was then applied according to the manufacture instructions, the restorative material was placed into the cavity incrementally using a non-metallic instrument and the first $1 \mathrm{~mm}$ layer were placed and adapted to the proximal box to aid in adaptation to all of the internal cavity aspects then each increment were cured by exposing it to a high intensity visible light source for 20 seconds keeping that the tip of the light guide should be held as close to the restorative as possible during light exposure, then finishing was done to contour the restoration surfaces.

\section{For Compomer restoration:}

The Prime \& Bond NT (Dentsply Sirona, Susquehanna Commerce Center, 221 West Philadelphia Street, Suite 60W, York, PA 17401) adhesive system was applied after conditioning the prepared tooth with NRC Non-Rinse Conditioner according to the manufacture instructions as follow:

Applying sufficient amount of NRC (Dentsply Sirona, Susquehanna Commerce Center, 221 West Philadelphia Street, Suite 60W, York, PA 17401) with a disposable brush to the all surfaces, leave undisturbed for 20 seconds without rinsing then remove excess NRC by blowing gently with an air syringe without desiccating the dentin structure. After conditioning the dentin surface, one layer of the Prime \& Bond NT was applied by dispensing it into a disposable brush and immediately applied to thoroughly wet all tooth surfaces. This surface should be saturated which may necessitate additional application of Prime \& Bond NT. Leaving the surface undisturbed for 20 seconds then remove solvent by blowing with air for at least 5 seconds leaving a uniform and glossy appearance surface then light cured for a minimum of 10 seconds. After insertion of compule tip into the notched opening of the applicator gun barrel, Dyract eXtra (Dentsply Sirona, Susquehanna Commerce Center, 221 West Philadelphia Street, Suite 60W, York, PA 17401) was dispensed directly into the cavity. Each increment was cured separately with a curing light for at least 40 seconds keeping that the tip of the light guide should be held as close as possible to the restoration during curing to be sure that each area of the entire restoration was exposed to the curing light. Finish- 
ing was done immediately after curing and gross excess material was removed with fluted finishing burs or diamonds.

All specimens were then, subjected to 300 thermocycles in water between $(5 \pm 5){ }^{\circ} \mathrm{C}$ and $(50 \pm 5){ }^{\circ} \mathrm{C}$ with a dwell time of 30 seconds in each bath and a 13 seconds transfer time between baths.

Five teeth were selected to get five dentin surfaces for compositional analysis of dentin surface by Infrared Spectroscopy. The dentin surfaces were etched with $35 \%$ phosphoric acid gel for 15 seconds and then the surfaces were thoroughly rinsed with water for another 10 seconds and air dried with oil free air. Infrared analysis was performed using Bruker FT.IR Vector22 (Bruker Optik GmbH in Ettlingen, Rudolf-Plank-Str. 27, 76275 Ettlingen, Germany) infrared spectroscope. The disk was prepared by mixing $2 \%$ of Potassium Bromide powder with finely grounded dentin, and the mix was packed in a stainless-steel die and compressed in a hydraulic press to form a transparent disc about $1 \mathrm{Cm}$ in diameter. The absorption band in the range of $400 \mathrm{Cm}^{1}$ - to $4200 \mathrm{Cm}^{1}$ - for of each disc was recorded in a graph and got tabulated.

Five teeth were selected to get five dentin surfaces for scanning electron microscope (SEM) (JEOL JSM-T330A, JEOL USA, Inc.11DearbornRoad, Peabody, MA 01960) assessment. Standardized surface finishing of dentin surfaces was done by using a silicon carbide paper 600 fine grit and then all dentin surfaces were etched with $35 \%$ phosphoric acid gel for 15 seconds, then the surfaces were thoroughly rinsed with water for another 10 seconds and air dried with oil free air.

\section{Group II (Laser etching group)}

This group contained ninety teeth. Twenty teeth were selected for assessment of microleakage and subdivided equally into two subgroups according to the type of restorative filling materials into:

(a) Ten teeth were restored with composite filling material. (b) Ten teeth were restored with compomer filling material.

A standardized rectangular class $\mathrm{V}$ cavity preparation was performed in the same manner as in acid etching group. The cleaned cavity was then etched using laser with water coolant to obtain a surface topography that could be favorable for bonding to the restorative filling materials. Laser parameters were set to deliver a beam of $3 \mathrm{~W}$ as power, pulse frequency of $2 \mathrm{~Hz}$, and pulse duration of $30 \mathrm{msec}$. in a focused mode at a constant distance. Laser interaction with the dentin surfaces was seen as pluming light and heard as a popping sound. Bonding and filling of restorative materials were then performed following the same steps as in acid etching group.

Thirty teeth were selected to get thirty dentin surfaces for compositional analysis of dentin surface by Infrared Spectroscopy (IS). The dentin surfaces were laser etched using different parameters with and without water coolant.

These surfaces were subdivided equally into six subgroups (IS subgroups) in which each subgroup contained five teeth:

IS subgroup 1: Laser etching using $1 \mathrm{~W}$.

IS subgroup 2: Laser etching using $1 \mathrm{~W}$ with water coolant.

IS subgroup 3: Laser etching using $2 \mathrm{~W}$.

IS subgroup 4: Laser etching using $2 \mathrm{~W}$ with water coolant.

IS subgroup 5: Laser etching using $3 \mathrm{~W}$.

IS subgroup 6: Laser etching using $\mathrm{W}$ with water coolant.

Thirty teeth were selected to get thirty dentin surfaces SEM assessment. The dentin surfaces were laser etched with different parameters with and without water coolant.

These surfaces were subdivided equally into six subgroups (SEM subgroups) in which each subgroup contained five teeth: 
SEM subgroup 1: Laser etching using $1 \mathrm{~W}$.

SEM subgroup 2: Laser etching using $1 \mathrm{~W}$ with water coolant.

SEM subgroup 3: Laser etching using $2 \mathrm{~W}$.

SEM subgroup 4: Laser etching using $2 \mathrm{~W}$ with water coolant.

SEM subgroup 5: Laser etching using $3 \mathrm{~W}$.

SEM subgroup 6: Laser etching using $3 \mathrm{~W}$ with water coolant.

\section{Group III (Control Group)}

Ten dentin surfaces of ten teeth were left untreated and subdivided into two groups:

(a) Five dentin surfaces for Infrared Spectroscopy assessment.

(b) Five dentin surfaces for SEM assessment.

All groups were assessed by the following assessment:

\section{(A) Microleakage Assessment:}

The restored teeth were used for assessment of microleakage by Dye penetration methods. The restored teeth were removed from distilled water and were dried using oil free compressed air. The crown and root of each tooth were completely coated with nail polish by means of a soft brush leaving the restoration and one millimeter in all directions around the margins exposed to the action of the tracing or dye solution, then, the teeth were immersed in $2 \%$ aqueous solution of methylene blue dye for 48 hours. The tracing solution was prepared by dissolving two gram of methylene blue powder in $100 \mathrm{ml}$ distilled water. Teeth were then removed from dye and rinsed thoroughly under running tap water until all dye solution was completely removed from the surface and then left to dry.

The teeth were longitudinally sectioned in a bucco-lingual direction using a slow speed diamond disc with coolant.
Both halves of each sectioned tooth were examined using a stereomicroscope to determine the extent of dye penetration at both the occlusal and gingival margins. Dye penetration along the gingival and occlusal margins was rated according to the following scores:

Score 0: indicated no dye penetration.

Score 1: dye penetration in enamel till DentinoEnamel Junction.

Score 2: dye penetration till pulpal or axial wall.

Score 3: dye penetration through pulpal or axial wall.

The obtained results were recorded, tabulated and statistically analyzed.

\section{(B) Infrared Spectroscopy Assessment:}

Each transparent disc was analyzed and the absorption band in the range from $400 \mathrm{Cm}^{1}-$ to 4200 $\mathrm{Cm}^{1}-$ for each group was recorded and tabulated.

\section{(C) Scanning Electron Microscope Assessment:}

The teeth of all groups were prepared and examined by SEM to evaluate the morphologic pattern and structural changes of the acid etched dentin, laser etched dentin and untreated dentin as well as microleakage study of the acid etched dentin and laser etched dentin. Then the results were recorded photographically.

\section{RESULTS}

\section{Microleakage analysis:}

The dye penetration scores of each filling material at both occlusal and gingival surfaces were recorded. The number of teeth and the penetration percentage of both surfaces in each score were also calculated and tabulated. Statistical analysis of dye penetration scores was performed using non-parametric test (One-Sample Kolmogorov-Smirnov Test) at $P \geq 0.001$. Mean and Standard deviation of dye penetration scores were also recorded, and the results were as follows: 


\section{Group I (Acid etching group)}

Dye penetration scores of the filling materials in group I at different surfaces including mean and standard deviation at $\mathrm{P} \geq 0.001$ are shown in table (1). The distribution of dye penetration scores for group I was shown in figure (1).

\section{Group II (Laser etching group)}

Dye penetration scores of the filling materials in group II at different surfaces including mean and standard deviation at $\mathrm{P} \geq 0.001$ are shown in table (2). The distribution of dye penetration scores for group I was shown in figure (2).

TABLE (1) Dye penetration scores of the filling materials in group I at different surfaces including mean and standard deviation at $\mathrm{P} \geq 0.001$.

\begin{tabular}{|c|c|c|c|c|c|c|}
\hline \multirow{2}{*}{$\begin{array}{c}\text { Dye } \\
\text { penetration } \\
\text { score }\end{array}$} & \multicolumn{2}{|c|}{$\begin{array}{l}\text { Number of teeth and } \\
\text { Penetration percentage in } \\
\text { Composite filling }\end{array}$} & \multicolumn{2}{|c|}{$\begin{array}{l}\text { Number of teeth and } \\
\text { Penetration percentage in } \\
\text { Compomer filling }\end{array}$} & \multicolumn{2}{|c|}{ Group I (Acid etching group) } \\
\hline & occlusal & gingival & occlusal & gingival & & \\
\hline \multirow{2}{*}{ Score 0} & $9(90 \%)$ & $3(30 \%)$ & $8(80 \%)$ & $3(30 \%)$ & \multirow{4}{*}{ Mean \pm SD } & \multirow{4}{*}{$0.48 \pm 0.599$} \\
\hline & & & & & & \\
\hline \multirow{2}{*}{ Score 1} & $1(10 \%)$ & $7(70 \%)$ & $2(20 \%)$ & $5(50 \%)$ & & \\
\hline & \multicolumn{2}{|c|}{$8(40 \%)$} & \multicolumn{2}{|c|}{$7(35 \%)$} & & \\
\hline \multirow{2}{*}{ Score 2} & $0(0 \%)$ & $0(0 \%)$ & $0(0 \%)$ & $2(20 \%)$ & \multirow{4}{*}{ P-value } & \multirow{4}{*}{0.000} \\
\hline & & & & & & \\
\hline \multirow{2}{*}{ Score 3} & $0(0 \%)$ & $0(0 \%)$ & $0(0 \%)$ & $0(0 \%)$ & & \\
\hline & \multicolumn{2}{|c|}{$0(0 \%)$} & \multicolumn{2}{|c|}{$0(0 \%)$} & & \\
\hline
\end{tabular}

TABLE (2) Dye penetration scores of the filling materials in group II at different surfaces including mean and standard deviation at $\mathrm{P} \geq 0.001$.

\begin{tabular}{|c|c|c|c|c|c|c|}
\hline \multirow[t]{2}{*}{$\begin{array}{l}\text { Dye penetration } \\
\text { score }\end{array}$} & \multicolumn{2}{|c|}{$\begin{array}{l}\text { Number of teeth and } \\
\text { Penetration percentage in } \\
\text { Composite filling }\end{array}$} & \multicolumn{2}{|c|}{$\begin{array}{l}\text { Number of teeth and } \\
\text { Penetration percentage in } \\
\text { Compomer filling }\end{array}$} & \multicolumn{2}{|c|}{$\begin{array}{l}\text { Group I (Acid etching } \\
\text { group) }\end{array}$} \\
\hline & occlusal & gingival & occlusal & gingival & & \\
\hline \multirow{2}{*}{ Score 0} & $7(70 \%)$ & $2(20 \%)$ & $6(60 \%)$ & $0(0 \%)$ & \multirow{4}{*}{ Mean \pm SD } & \\
\hline & & & & & & 1090 \\
\hline \multirow{2}{*}{ Score 1} & $3(30 \%)$ & $2(20 \%)$ & $4(40 \%)$ & $0(0 \%)$ & & $1.00 \pm 0.911$ \\
\hline & \multicolumn{2}{|c|}{$5(25 \%)$} & \multicolumn{2}{|c|}{$4(20 \%)$} & & \\
\hline \multirow{2}{*}{ Score 2} & $0(0 \%)$ & $6(60 \%)$ & $0(0 \%)$ & $8(80 \%)$ & \multirow{4}{*}{ P-value } & \multirow{4}{*}{0.019} \\
\hline & & & & & & \\
\hline \multirow{2}{*}{ Score 3} & $0(0 \%)$ & $0(0 \%)$ & $0(0 \%)$ & $2(20 \%)$ & & \\
\hline & \multicolumn{2}{|c|}{$0(0 \%)$} & \multicolumn{2}{|c|}{$2(10 \%)$} & & \\
\hline
\end{tabular}




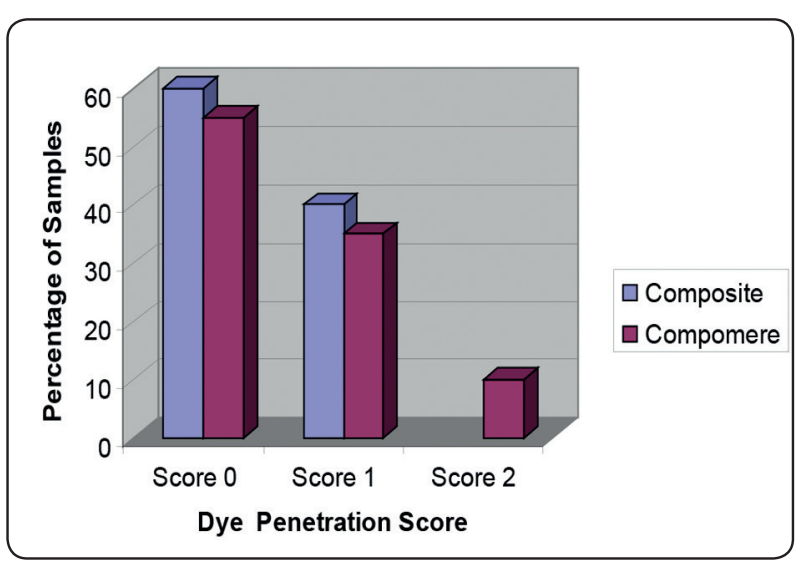

Fig. (1) Distribution of dye penetration scores for group I.

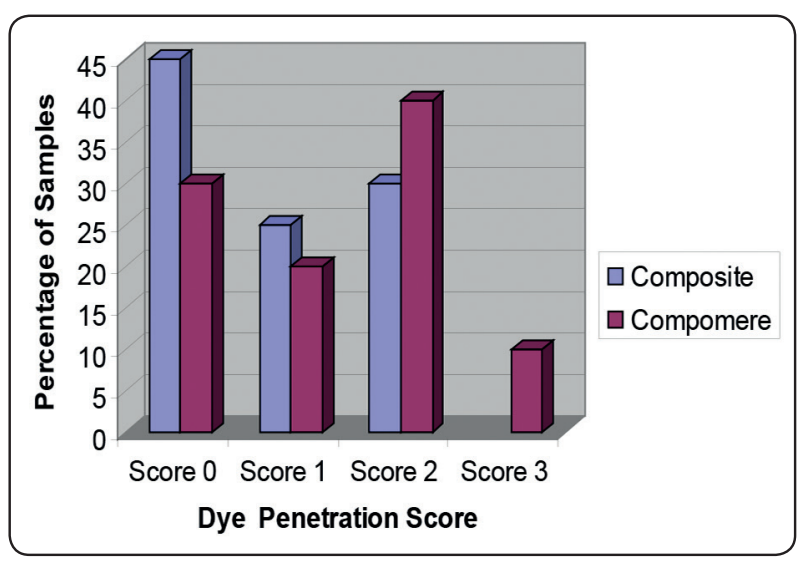

Fig. (2) Distribution of dye penetration scores for laser Etching group.

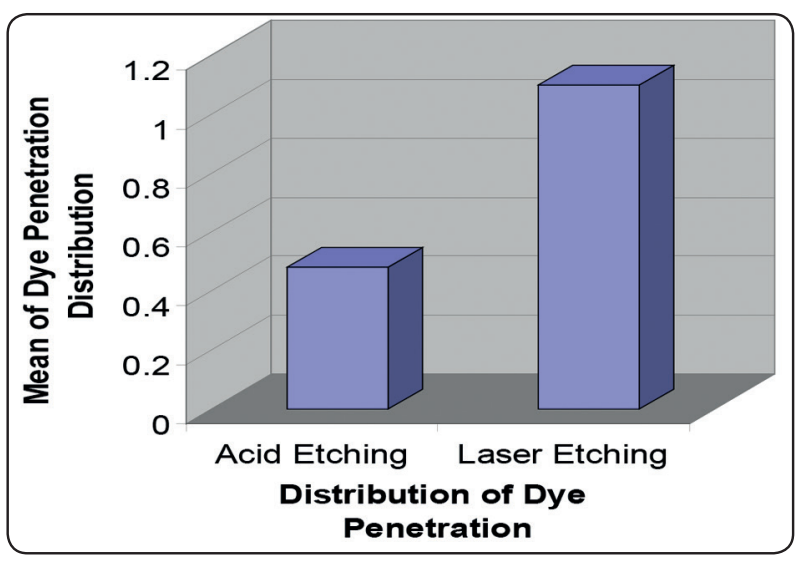

Fig. (3) Dye Penetration distribution among Acid and Laser Etching groups
The results showed a high significant difference in dye penetration scores of group II $(\mathrm{P}=0.019)$ compared to group I $(\mathrm{P}=0.000)$

The distribution of dye penetration scores for groups I (acid Etching group) and II (laser Etching group) was shown in figure (3).

Upon comparing groups I and II according to the filling materials, the results showed that the acid etching of composite was more significant than laser etching which was non-significant. For compomer, the results showed that the conditioning of compomer filling was more significant than laser etching as shown in table (3).

TABLE (3) Mean \pm SD of groups I and II

\begin{tabular}{|c|c|c|c|}
\hline \multicolumn{2}{|c|}{ Filling material } & $\begin{array}{c}\text { Acid etching } \\
\text { group }\end{array}$ & $\begin{array}{c}\text { Laser } \\
\text { etching } \\
\text { group }\end{array}$ \\
\hline \multirow{2}{*}{$\begin{array}{c}\text { Composite filling } \\
\text { material }\end{array}$} & Mean \pm SD & $0.503 \pm 0.40$ & $0.875 \pm 0.85$ \\
\cline { 2 - 4 } & P-value & 0.005 & 0.079 \\
\hline $\begin{array}{c}\text { Compomer } \\
\text { filling material }\end{array}$ & Mean \pm SD & $0.686 \pm 0.55$ & $1.031 \pm 1.30$ \\
\cline { 2 - 4 } & P-value & 0.020 & 0.160 \\
\hline
\end{tabular}

\section{Infra-red spectroscopy:}

The term Infra-red (IR) fundamental region is often used to describe the wavelength region from $4200 \mathrm{~cm}^{1}$ - to $400 \mathrm{~cm}^{1}$ - of light spectrum. Most of the absorption bands observed in this region correspond to quantize uptake of energy into the fundamental vibration modes of the molecules under study. As a result of the acid etching and laser etching applications, the intensity of the bands was affected as compared with the normal dentin. The absorption bands of a group can be remarkably shifted owing to a number of factors specially those which change the force constant of bands. The variation in the structure as studied by IR spectroscopy appears in the form of a difference in intensities of bands, shifting and/or appearance of new bands. 
There was a decrease in the intensity of bands with shifting to a lower level in case of acid etched dentin surface more than in case of laser etching and both were less than the control group.

Upon comparing laser application on dentin with and without water, it was found that the intensity of both bands was decreased in case of laser application without water. With increasing of laser parameters, there was a decrease in the intensity of the bands.

The IR spectra of the dentin surface of each group are presented by the frequencies of the wave number of the absorption bands together with their relative intensities of the dentin in tables 4 to 11 .

TABLE (4) Absorption bands with their relative intensities in control group.

\begin{tabular}{|c|c|}
\hline $\begin{array}{l}\text { Wave number } \\
\qquad\left(\mathrm{cm}^{-1}\right)\end{array}$ & $\begin{array}{c}\text { Relative intensities } \\
\text { (Absorbance unit) }\end{array}$ \\
\hline 3346.4 & 0.738 \\
\hline 1645.8 & 0.356 \\
\hline 1457.7 & 0.642 \\
\hline 1418.1 & 0.164 \\
\hline 1090.9 & 0.142 \\
\hline 1078.1 & 0.201 \\
\hline 1054.9 & 0.130 \\
\hline 1047.2 & 0.940 \\
\hline 1036.7 & 4.343 \\
\hline 1022.3 & 0.110 \\
\hline 1011.1 & 0.110 \\
\hline 871.9 & 0.173 \\
\hline 604.9 & 0.428 \\
\hline 568.5 & 1.459 \\
\hline 420.0 & 0.076 \\
\hline
\end{tabular}

TABLE (5) Absorption band with their relative intensities of acid etched group

\begin{tabular}{|c|c|}
\hline $\begin{array}{c}\text { Wave number } \\
\left(\mathrm{cm}^{-1}\right)\end{array}$ & $\begin{array}{c}\text { Relative intensities } \\
\text { (Absorbance unit) }\end{array}$ \\
\hline 3854.8 & 0.026 \\
\hline 3386.6 & 0.435 \\
\hline 2366.5 & 0.029 \\
\hline 2344.7 & 0.027 \\
\hline 1654.8 & 0.184 \\
\hline 1543.3 & 0.043 \\
\hline 1458.1 & 0.435 \\
\hline 1418.8 & 0.106 \\
\hline 1034.4 & 1.971 \\
\hline 959.8 & 0.046 \\
\hline 872.0 & 0.117 \\
\hline 603.6 & 0.337 \\
\hline 563.3 & 1.052 \\
\hline
\end{tabular}

TABLE (6) Absorption band with their relative intensities in Laser group using 1 Watt

\begin{tabular}{|c|c|}
\hline $\begin{array}{c}\text { Wave number } \\
\left(\mathrm{cm}^{1-}\right)\end{array}$ & $\begin{array}{c}\text { Relative intensities } \\
(\text { Absorbance unit })\end{array}$ \\
\hline 3380.4 & 0.834 \\
\hline 1655.9 & 0.314 \\
\hline 1457.1 & 0.742 \\
\hline 1416.6 & 0.186 \\
\hline 1064.4 & 0.093 \\
\hline 1052.8 & 0.485 \\
\hline 1032.9 & 3.908 \\
\hline 873.2 & 0.185 \\
\hline 604.0 & 0.552 \\
\hline 563.6 & 1.798 \\
\hline
\end{tabular}

TABLE (7) Absorption band with their relative intensities in Laser group using 1 Watt with water coolant

\begin{tabular}{|c|c|}
\hline $\begin{array}{c}\text { Wave number } \\
\left(\mathrm{cm}^{-1}\right)\end{array}$ & $\begin{array}{c}\text { Relative intensities } \\
(\text { Absorbance unit })\end{array}$ \\
\hline 3398.4 & 0.599 \\
\hline 2922.9 & 0.063 \\
\hline 1657.3 & 0.497 \\
\hline 1544.8 & 0.041 \\
\hline 1456.0 & 0.350 \\
\hline 1418.4 & 0.094 \\
\hline 1032.7 & 1.516 \\
\hline 872.3 & 0.123 \\
\hline 603.7 & 0.221 \\
\hline 563.6 & 0.851 \\
\hline
\end{tabular}


TABLE (8) Absorption band with their relative intensities of Laser group using 2 Watts

\begin{tabular}{|c|c|}
\hline $\begin{array}{c}\text { Wave number } \\
\left(\mathrm{cm}^{-1}\right)\end{array}$ & $\begin{array}{c}\text { Relative intensities } \\
\text { (Absorbance unit) }\end{array}$ \\
\hline 3855.2 & 0.024 \\
\hline 3385.8 & 0.295 \\
\hline 2367.4 & 0.026 \\
\hline 2344.9 & 0.025 \\
\hline 1654.8 & 0.123 \\
\hline 1543.4 & 0.027 \\
\hline 1458.1 & 0.294 \\
\hline 1419.4 & 0.070 \\
\hline 1034.9 & 1.354 \\
\hline 959.6 & 0.034 \\
\hline 872.1 & 0.077 \\
\hline 603.9 & 0.253 \\
\hline 563.8 & 0.732 \\
\hline & \\
\hline & \\
\hline
\end{tabular}

TABLE (9) Absorption band with their relative intensities of Laser group using 2 Watts with water coolant

\begin{tabular}{|c|c|}
\hline $\begin{array}{c}\text { Wave number } \\
\left(\mathrm{cm}^{-1}\right)\end{array}$ & $\begin{array}{c}\text { Relative intensities } \\
\text { (Absorbance unit) }\end{array}$ \\
\hline 3352.4 & 0.795 \\
\hline 1654.8 & 0.361 \\
\hline 1543.6 & 0.068 \\
\hline 1457.9 & 0.727 \\
\hline 1419.0 & 0.057 \\
\hline 1032.0 & 2.412 \\
\hline 871.9 & 0.164 \\
\hline 603.1 & 0.324 \\
\hline 561.4 & 1.365 \\
\hline
\end{tabular}

Table (10) Absorption band with their relative intensities of Laser group using 3 Watts

\begin{tabular}{|c|c|}
\hline $\begin{array}{c}\text { Wave number } \\
\left(\mathrm{cm}^{-1}\right)\end{array}$ & $\begin{array}{c}\text { Relative intensities } \\
\text { (Absorbance unit) }\end{array}$ \\
\hline 3904.5 & 0.012 \\
\hline 3855.0 & 0.025 \\
\hline 3751.7 & 0.016 \\
\hline 3341.3 & 0.566 \\
\hline 2345.2 & 0.023 \\
\hline 1654.9 & 0.514 \\
\hline 1560.3 & 0.023 \\
\hline 1543.4 & 0.060 \\
\hline 1508.3 & 0.016 \\
\hline 1458.1 & 0.288 \\
\hline 1420.3 & 0.077 \\
\hline 1031.5 & 1.182 \\
\hline 871.8 & 0.103 \\
\hline 603.7 & 0.150 \\
\hline 562.7 & 0.702 \\
\hline
\end{tabular}

TABLE (11) Absorption band with their relative intensities of Laser group using 3 Watts with water coolant

\begin{tabular}{|c|c|}
\hline $\begin{array}{c}\text { Wave number } \\
\left(\mathrm{cm}^{-1}\right)\end{array}$ & $\begin{array}{c}\text { Relative intensities } \\
\text { (Absorbance unit) }\end{array}$ \\
\hline 3387.2 & 0.606 \\
\hline 1654.8 & 0.250 \\
\hline 1458.1 & 0.630 \\
\hline 1419.1 & 0.059 \\
\hline 1.032 & 2.369 \\
\hline 871.9 & 0.151 \\
\hline 603.6 & 0.333 \\
\hline 563.2 & 1.284 \\
\hline
\end{tabular}

\section{Scanning Electron Microscope (SEM):}

Control group samples showed heavy deposits of smeared layer cover dentin surface with some detached areas, with few holes in the underlying dentin reflect the openings of some dentinal tubules.

More openings of the dentinal tubules were observed in case of acid etching group on the dentin surface with uniform appearance. 
Laser irradiation produced changes in surface morphology. Laser etching of the dentin surface without water spray produced a surface melting and recrystallisation of smeared layer with fusion of crystals, while in case of laser etching of the dentin surface with water spray showed islands of crystals with different sizes and less degree of fusion of crystals as well as opening of the dentinal tubules and voids. It was apparent that with increasing laser parameter, more fusion of the crystals was found, in addition to the occurrence of cracks and craters on dentin surface.

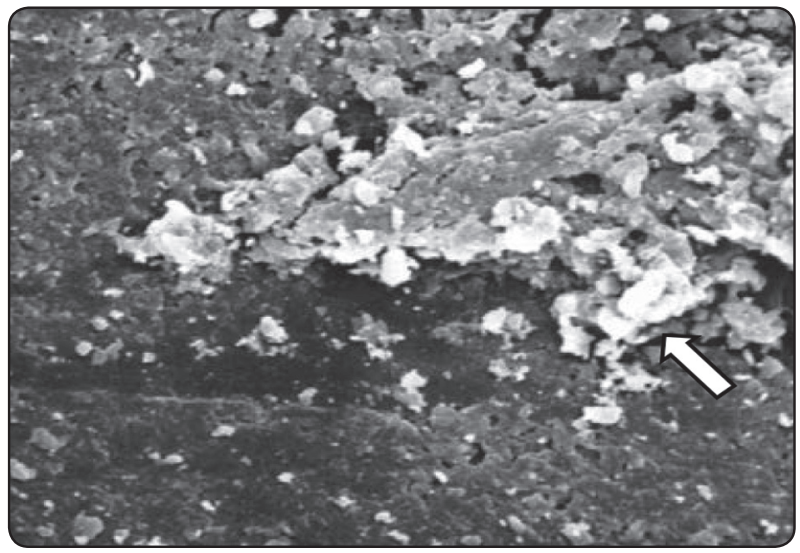

Fig. (4) Heavy deposits of smeared layer cover dentin surface with some detached areas with few holes in the underlying dentin reflect the openings of some dentinal tubules (Mag. 1000x).

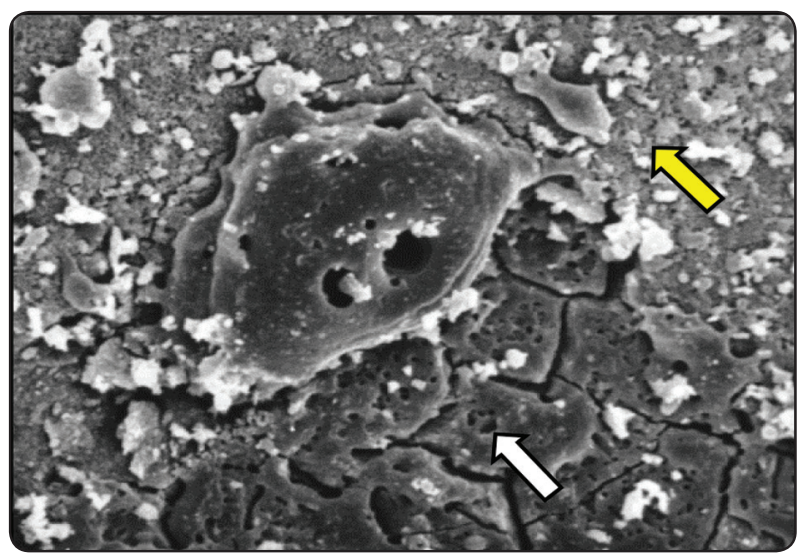

Fig. (6) laser etching of dentin at 1 watt with the transitional zone between lased and un-lased area. Lased area (White arrow) appears with a distinctive squamous pattern with absence of the smeared layer and few openings of dentinal tubules appear within the molten re-solidified dentin while the un-lased area (Yellow arrow) is covered with deposits of smeared layer (Mag. 1000x).
The bonding agent penetrates along the etching area which was more apparent in case of acid etching with composite filling, and to a less degree in case of compomer filling material.

More fusion and formation of thick hybrid layer in case of acid etching with composite filling than that in case of compomer filling material.

Upon comparing the interfaces in case of acid etching with that of laser etching, there was more gap at the interface with laser etching than that of acid etching.

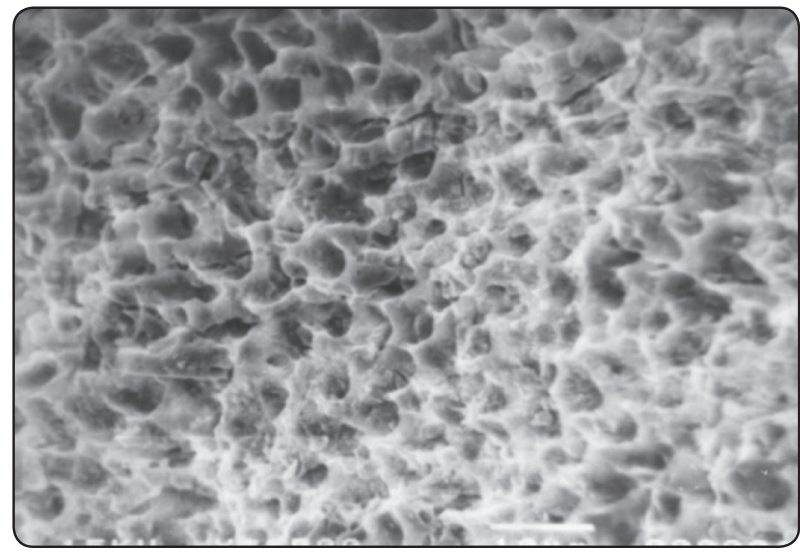

Fig. (5) Uniform appearance of dentinal tubules openings appears on dentin surface of acid etched group (Mag. 2500x).

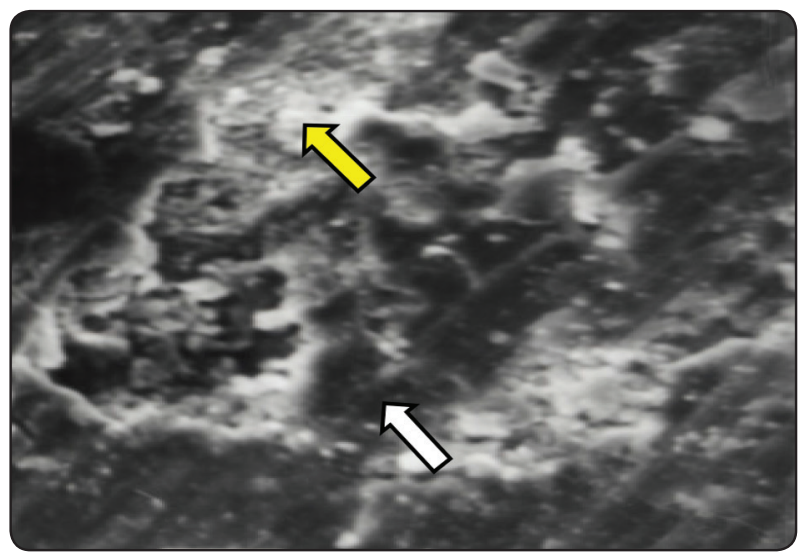

Fig. (7) Laser etching of dentin with 1watt using water shows crystals of different sizes and less degree of fusion between crystals as well as some openings of the dentinal tubules and voids. The transitional zone between lased (White arrow) and un-lased area (Yellow arrow) is less obvious (Mag. 1000x). 


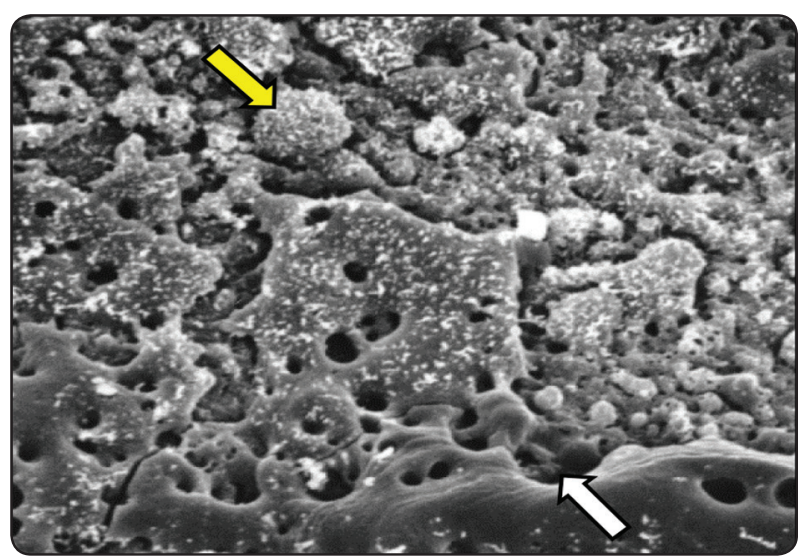

Fig. (8) Laser etching of dentin at 2 watts. The transitional zone shows deep dentin craters (White arrow) caused by evaporation of some dentin spots, granular smeared layer (Yellow arrow) covers the peripheries of the area directly affected by laser irradiation (Mag. 1000x).

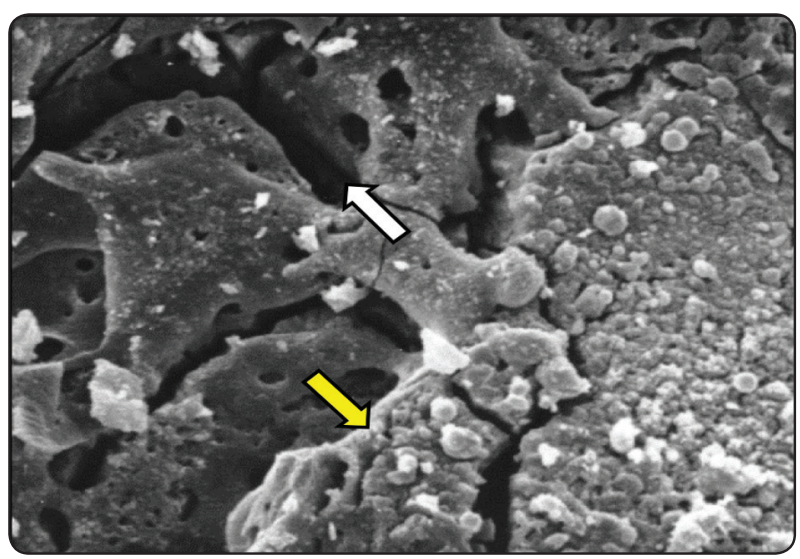

Fig. (10) Laser etching of dentin using 3 watts. The transitional zone shows deep dentin craters (White arrow) caused by evaporation of some dentin spots, granular smeared layer (Yellow arrow) covers the peripheries of the area directly affected by laser irradiation (Mag. 1000x).

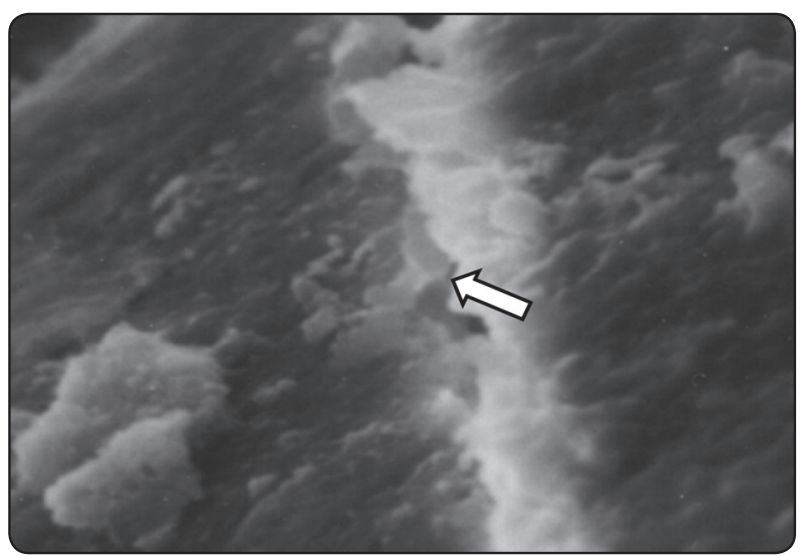

Fig. (12) Bonding area (White arrow) of acid etched dentin and composite filling material (Mag. 1000x).

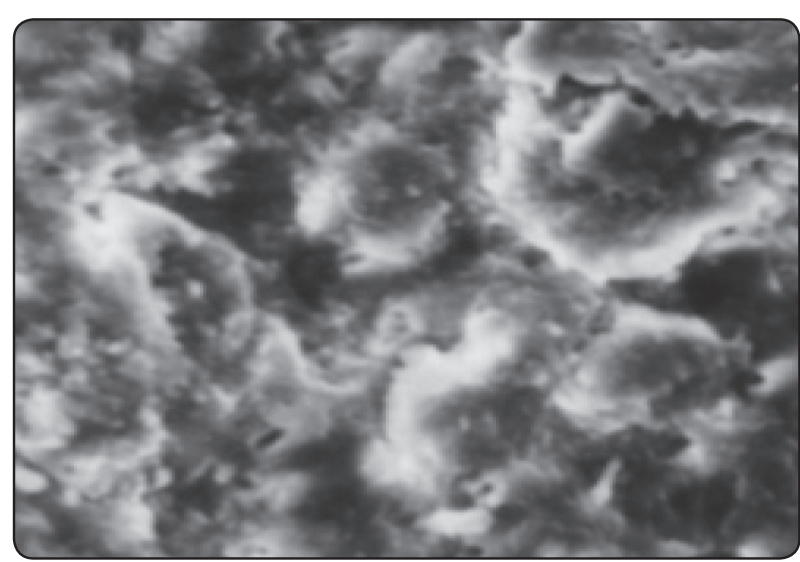

Fig. (9) Laser etching of dentin at 2watt with water. Dentin surface shows crystals of different sizes and less degree of fusion between crystals. Transitional zone is less obvious (Mag. 1000x).

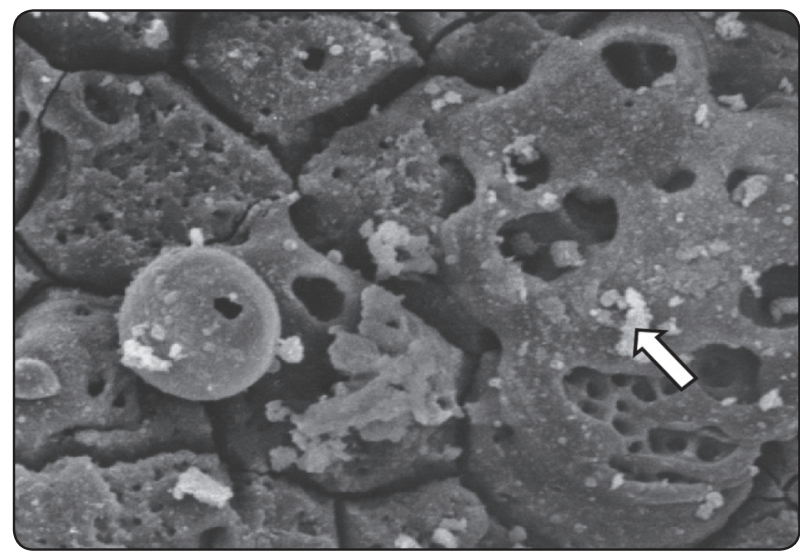

Fig. (11) Laser etching of dentin using 3watts with water. Dentin surface shows absence of smeared layer except for few debris (White arrow). Craters are less obvious than in absence of water coolant (Mag. 1000x).

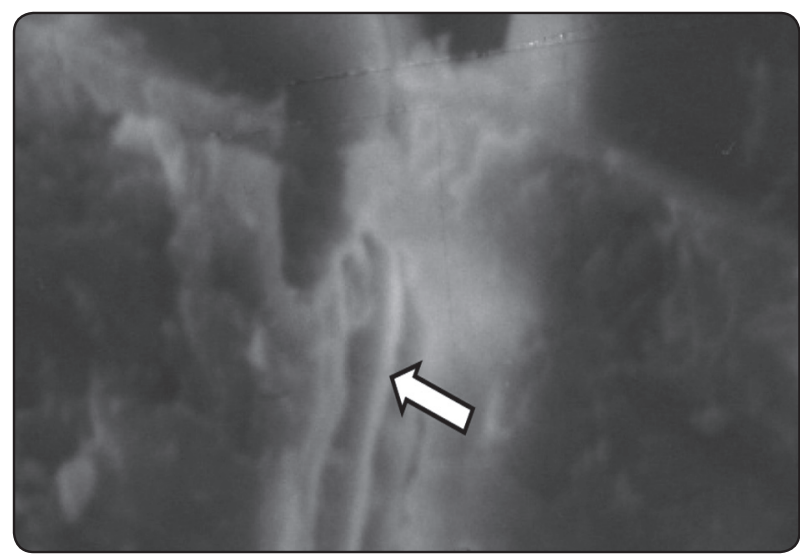

Fig. (13) Bonding area (White arrow) of laser etched dentin (White arrow) and composite filling material (Mag. 1000x). 


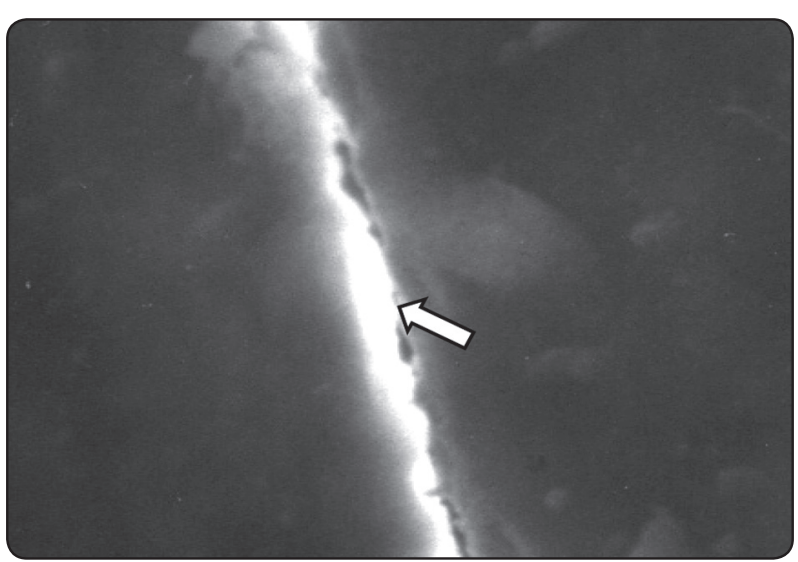

Fig. (14) Bonding area (White arrow) of conditioned dentin and compomer filling material (Mag. 1000x).

\section{DISCUSSION}

This study was carried out to evaluate the effect of acid etching versus laser etching surface treatment of dentin on the bonding of two restorative filling materials (Composite and Compomer) to dentin surface by increasing the surface area through micro-roughening of tooth.

Dentin surface etching was proved to be an adhesion promoter, enhancing the penetration of monomers into demineralized dentine to form a hybrid layer and the quality of the bond depends upon the ability of the monomers to penetrate throughout to dentin ${ }^{(19)}$.

The acid chosen for our etching procedures in composite filling material was phosphoric acid as it was found that it removes more calcium hydroxyapatite crystals and thus gives more microroughness when compared by the other acids as citric acid and maleic acid. This was in agreement with Di Renzo, et al, $2001^{(20)}$ and Bagmar S, et al, $2013^{(21)}$.

The laser was considered a newer surface treatment modality to acid etching thus its effect on enhancement of bond strength had to be investigated. There is a great variety of lasers existing, each differing from the other by the emitted wavelength. The laser-matter interaction is not only wavelength

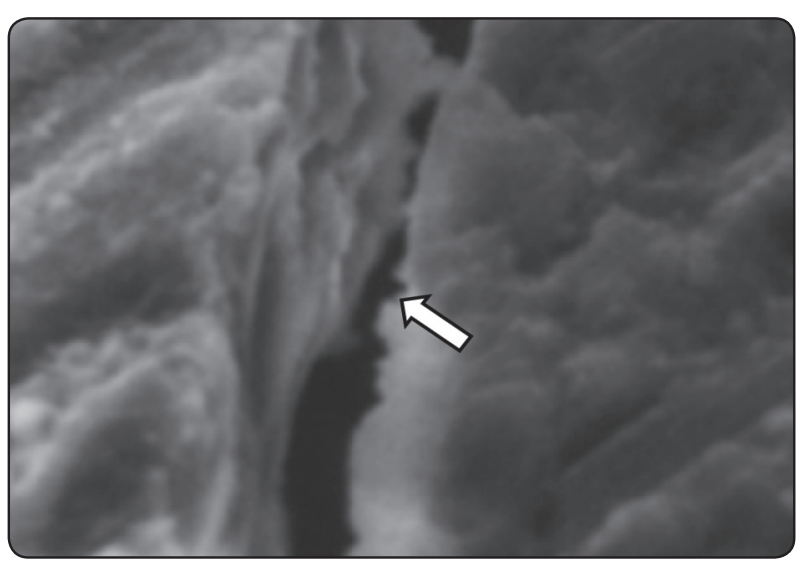

Fig. (15) Bonding area (White arrow) of laser etched dentin and compomer filling material (Mag. 1000x)

dependent, but also the laser power settings, pulse duration, and the matter optical properties ${ }^{(22)}$.

The type of laser used in this study was a Carbon dioxide laser, mid IR range, which got FDA approval as an infrared laser system for dental use. It has been vastly investigated for soft and some hard tissue applications, including cavity preparation and surface alteration. Amongst their advantages are their availability, safety, and ease of maintenance and their malleable delivery systems. It is also shows strong absorption by hydroxyapatite, therefore is highly suitable for application on dental hard tissues ${ }^{(23)}$.

The laser parameter used in this study for laser etching in assessment for microleakage was in agreement with Andrea, et al $2000^{(24)}$.

Assessment of microleakage was done by using dye penetration method which is continued to be the most popular techniques that it is currently available, as it allows the production of sections showing leakage in contrasting colors to both tooth and restoration without the need for further chemical reaction or exposure to potentially hazardous reaction as revealed by Tylor and Lynch in $1992^{(25)}$, Magalhães et al, $1999^{(26)}$ and Morais et al, $1999^{(27)}$.

Dye penetration method was done using $2 \%$ aqueous solution of methylene blue on the basis 
of its advantage over other tracing materials. It is very soluble in water, easily penetrates the water compartment of the tooth, does not adsorb to the dental matrix or apatite crystals and penetrates further than any of the isotope tracing. This was in agreement with Matloff, $1982^{(28)}$.

The results obtained by dye penetration method revealed that the $\mathrm{CO} 2$ laser etching produced the highest leakage scores than the acid etching. This could be attributed to that the acid etching of the dentin caused removal of the smear layer, opens the dentinal tubules in a funnel configuration and exposes both intertubular and peritubular collagen by the formation of micropores in the inter and peritubular dentin which is the most affected since it contains the highest mineral content. This was further substantiated by the SEM which revealed, in case of phosphoric acid etching, complete removal of the smear system, widening of the dentinal tubules orifices with no smear plugs, the acid preferentially dissolved the peritubular dentin to create funnelshaped dentinal tubules orifices. While Laser etching of dentin caused surface melting and loss of dentin surface architecture as a result of micro-explosions produced by the $\mathrm{CO}^{2}$ laser due to its thermomechanical ablation. This was further confirmed by the SEM observations which revealed localized surface melting, microcracks and fissures with no evidence of opened dentinal tubules orifices. These changes would deprive the filling material from the retentive micromechanical undercuts and decrease its bond strength to dentin. So, although the laser etching roughened the surface of dentin, it did not provide a surface as retentive as a surface treated with conventional acid etching. This was in agreement with Mohsen and Shabka, $1993{ }^{(29)}$, Ariyaratnam et al, $1997^{(30)}$ and Armengol, $2003^{(31)}$.

Acid etching produced the lowest leakage scores than the other types of laser etching such as Eximer Laser as reported by Yazici, et al, in 2001 $1^{(32)}$ and Er:YAG and Nd:YAP Laser as reported by Armengol, et al, in $2002^{(33)}$.
The results obtained by dye penetration method revealed that there was a lesser leakage scores at occlusal site in compared to the gingival site for the acid etching and the laser etching groups. This was in agreement with the finding of Amsberry et al, $1984^{(34)}$ and Fayyad and Shortall, $1987^{(35)}$.

This could be related to the presence of adequate enamel thickness at the occlusal site which is necessary for successful bonding while the enamel at the gingival site cannot offer a bond which can resist stresses due to polymerization shrinkage of the restorative materials. This was in agreement with Jordan, $1992^{(36)}$.

The difference in orientation of dentinal tubules, which is nearly parallel to the prepared surface at the occlusal site and perpendicular at the gingival site, might also contribute to these results. This difference in orientation could lead to more tubules connected to the cut surface at the gingival site providing hybrid layer of lesser quality. These results were in agreement with Yap et al, $1995^{(37)}$, Hilton and Ferrancane, $1998^{(38)}$, and Estafan et al, $2000^{(39)}$.

The results obtained by IR Spectroscopy revealed that there was a decreased of the intensity of spectral bands in case of acid etching and laser etching of dentin surface than the control group. The spectral bands were decreased in intensity in case of acid etching more than laser etching of dentin. This may be attributed to the chemical effect of acid on the dentin which caused dissolution of calcium hydroxyapatite (HAP) of the dentin surface as explained by Di Renzo et al, 2001, and the obtained effect of the laser was attributed to the ablation effect of laser energy on dentin surface.

The results obtained by Scanning Electron Microscope revealed that the acid etching of dentin caused removal of the smear layer and the superficial part of dentin exposing the apertures of dentinal tubules, demineralize the dentin surface and increase the microporosities of the intertubular 
dentin by exposing the dentinal collagen network. This was in agreement with Bertolotti, $1992^{(40)}$, Van Meerbeek et al, $1992^{(41)}$, Perdigao et al, $1994^{(42)}$, Matos et al, $1997^{(43)}$, and Gateva et al, $2016^{(44)}$.

However, laser etching of dentin showed irregular sealing of orifices of dentinal tubules and melting of mineral phase, as a $\mathrm{CO}_{2}$ laser exposure of dentin decreased the organic composition of the surface, so that a recrystalization process had occurred that resulted in an increase in the size of the crystals. This was in agreement with Hedayatollahnajafi et al, $2009^{(45)}$.

Many studies have compared the bond strengths and surface morphology for $\mathrm{CO}_{2}$ laser etched enamel and dentin with conventional phosphoric acid etching, demonstrated that $\mathrm{CO}_{2}$ laser etching is weaker in bond strengths than acid etching. This was in agreement with Gateva et al, $2016^{(44)}$ Hedayatollahnajafi et al, $2009^{(45)}$. The bond strength between the filling material and tooth structure in case of acid etching were superior to other types of laser etching such as Nd:YAG Laser as reported by Ariyaratnam, et al, $1997^{(14)}$ and AbdullJabbar et al, $1993{ }^{(46)}$ and Er:YAG Laser as reported by De Munck et al, $2002^{(47)}$.

Andrea, et al $2000^{(24)}$, Staninec, et al $2009^{(48)}$ and Moretto' et al 2011 ${ }^{(49)}$ concluded that, there was no significant difference between $\mathrm{CO}_{2}$ laser etching used after phosphoric acid etching, $\mathrm{CO}_{2}$ laser etching used alone and phosphoric acid etching alone in microleakage using dye penetration, and these groups showed lower microleakage scores than group when the $\mathrm{CO}_{2}$ laser etching was used before phosphoric acid etching.

On the other hand, this finding contradicted that of Cooper et al, 1988, who reported that an increased in shear bond strength of composite to laser treated dentin due to the associated increase in surface roughness by the effect of $\mathrm{CO}_{2}$ laser beam, the source of contradiction might be attributed to the fact that in that study, $\mathrm{CO}_{2}$ lased dentin was only compared to untreated dentin and not to acid-etched dentin regarding surface roughness and shear bond strength to composite. Moreover, this finding also contradicted Groth et al, $2001{ }^{(50)}$, who claimed that laser irradiation could provide an effective and alternative method to the acid etching technique. The source of contradiction may be related to the difference in laser type, energy density and time of laser application.

\section{CONCLUSION}

From the previously mentioned, it could be concluded that acid etching of dentin gives better results on the bonding of Composite and Compomer filling materials and thus gives more successful clinical condition. Consequently, the laser etching when applied using the preset parameters has less etching and more damaging effect on dentin. Further investigations are needed by using different types of laser and different parameters to get more benefits from applications of laser clinically.

\section{RECOMMENDATION}

Further investigations are needed by using different types of laser to get more benefit from applications of laser clinically.

\section{REFERENCES}

1. Davari A, Sadeghi M, Bakhshi H. Shear bond strength of an etch-and-rinse adhesive to ER: YAG laser- and/or phosphoric acid-treated dentin. JODDD.2013;7(2):61-66

2. Van Meerbeek B, Inokoshi S, Braem M, Lambrechts P, Vanherle G. Morphological aspects of the resin-dentin inter diffusion zone with different adhesive systems. J Dent Res.1992;71(8):1530-1540.

3. Pashley DH, Tao I, Boyd I, King GE. Scanning electron microscopy of the substructure of smear layer in human dentin. Arch Oral Biol.1988; 33(4):265- 270.

4. Nakabayashi N, Kojima K, Masuhara E. The promotion of adhesion by infiltration of monomers into tooth substrates. J Biomed Mater Res.1982; 16(3):265-273. 
5. Nakabayashi N. Adhesive bonding with 4-META. Oper Dent.1992; 5:125-130.

6. Lee BS, Hsieh TT, Lee YL, Lan WH, Hsu YJ, Wen PH, et al. Bond strengths of the orthodontic bracket after acidetched, Er: YAG laser-irradiated and combined treatment on the enamel surface. Angle Orthod 2003; 73:565-70.

7. Gokcelik A, Ozer Y, Ozel E, Arhun N, Attar N, Firatli S, et al. The influence of Er: YAG laser conditioning versus self-etching adhesives with acid etching on the shear bond strength of orthodontic brackets. Photomed Laser Surg 2007; 25:508-12.

8. Berk N, Başaran G, Ozer T. Comparison of sandblasting, laser irradiation, and conventional acid etching for orthodontic bonding of molar tubes. Eur J Orthod 2008; 30:1839.

9. von Fraunhofer JA, Allen DJ, Orbell GM. Laser etching of enamel for direct bonding. Angle Orthod 1993; 63:73-6.

10. Martínez-Insua A, Da Silva Dominguez L, Rivera FG, Santana-Penín UA. Differences in bonding to acid-etched or Er: YAG-laser-treated enamel and dentin surfaces. J Prosthet Dent 2000; 84:280-8.

11. Uşümez $S$, Orhan $M$, Uşümez A. Laser etching of enamel for direct bonding with an Er, Cr: YSGG hydro kinetic laser system. Am J Orthod Dentofacial Orthop 2002; 122:649-56.

12. Convissar R A. Principles and Practice of Laser Dentistry, 1st edition 2011 St. Louis: Mosby Elsevier.

13. Wilder-Smith P, Dang J, and Kurosaki T: Investigating the range of surgical effects on soft tissue produced by a carbon dioxide laser. JADA1997 May; 128; 583-588.

14. Ariyaratnam MT, Wilson MA, Mackie IC, Blinkhorn AS (1997) A comparison of surface roughness and composite/enamel bond strength of human enamel following the application of the Nd: YAG laser and etching with phosphoric acid. Dent. Mater. 13: 51-55

15. Corpas-Pastor L, Moreno JV, Garrido JDDLG, Muriel VP, Moore K, et al. (1997) Comparing the tensile strength of brackets adhered to laser-etched enamel vs. acid-etched enamel. J Am Dent Assoc 128: 732-737.

16. Shahabi S, Brockhurst PJ, Walsh LJ (1997) Effect of toothrelated factors on the shear bond strengths obtained with $\mathrm{CO}_{2}$ laser conditioning of enamel. Aust Dent J 42: 81-84.
17. Melendez EJ, Arcoria CJ, Dewald JP, Wagner MJ (1992) Effect of laser etch on bond strengths of glass ionomers. J Prosthet Dent. 67: 307-312.

18. Walsh LJ, Ahood D, Brockhurst PJ (1994) Bonding of composite resin to carbon dioxide laser-modified human enamel. Dent Mater 10: 162-166.

19. Sabatini C (2013) Effect of phosphoric acid etching on the shear bond strength of two self-etch adhesives. J Appl Oral Sci 21(1):56-62.

20. Di Renzo M, Ellis TH, Sachet E and Stangel I (2001) A photoacoustic FTIRS study of the chemical modifications of human dentin surfaces: I. Demineralization. Biomaterials, 22: 787-792.

21. Bagmar S, Jadhav S, Hegde V and Srilatha S (2013) A comparative evaluation of different acids for removal of smear layer after cavity preparation. An in vitro study. IJRANSS 1(2):5-12

22. Katzir, A. (2012) Lasers and optical fibers in medicine. Academic press, Inc. A division of Harcourt Brace \& Co. 1250 Sixth Avenue, San Diego, California 92101-4311; 33-59.

23. Featherstone JDB. and Nelson DGA (1987) Laser effects on dental hard tissues. Adv. Dent. Res., 1: 21-26.

24. Andrea NL, Narciso GN, Adriana FP, Juliana M, Ricardo SN, Carlos E and Denise Z (2000) Microleakage in class V Composite resin restorations treated with $\mathrm{CO}_{2}$ Laser: An in vitro study. Laser in Dentistry VI, 3910: 128-133.

25. Taylor MJ and Lynch E (1992): Microleakage. J. Dent., 20: 3-10.

26. Magalhães CS, Serra MC and Rodrigues AL (1999) Volumetric microleakage assessment of glass-ionomer- resin composite hybrid materials. Quintessence Int 30: 117-121.

27. Morais PM, Rodrigues AL and Pimento LAF (1999) Quantitative microleakage evaluation around amalgam restorations with different treatments on cavity wall. Operative Dent 24: 217-222.

28. Matloff LA, Jensen JR, Singer L and Tabib, A (1982) A comparison of methods used in root canal sealability studies. Oral Surg 53: 203-208.

29. Mohsen MM and Shabka AA (1993) Dentin roughness after different surface treatments. Egypt Dent J 39(1):363-6.

30. Ariyaratnam MT, Wilson MA, Mackie IC, Blinkhorn AS (1997) A comparison of surface roughness and composite/ 
enamel bond strength of human enamel following the application of the Nd:YAG laser and etching with phosphoric acid. Dent Mater 13(1): 51-55.

31. Armengol V, Laboux 0, Weiss P, Jean A and Hamel H (2003) Effects of Er:YAG and Nd:YAP laser irradiation on the surface roughness and free surface energy of enamel and dentin: An In vitro study. J Oper Dent 28(1): 67-74.

32. Yazici AR, Frentzen M and Dayangac B (2001) In vitro analysis of the effects of acid or laser etching on microleakage around composite resin restorations. J Dent 29(5):355-61.

33. Armengol V, Jean A, Enkel B, Assoumou M and Hamel H. (2002) Microleakage of Class V Composite Restorations Following Er:YAG and Nd:YAP Laser Irradiation Compared to Acid-etch: an In Vitro Study. Lasers in Medical Science 17(2): 93-100.

34. Amsberry W, von Fraunhofer JA , Hoots J and Rodgers H. (1984) Marginal leakage of several acid-etch composite resin restorative systems. J Prosthet Dent 52:647-653.

35. Fayyad MA and Ball PC (1987) Bacterial penetration around amalgam restorations. J Prosthest Dent 57: 571574.

36. Jordan RE (1992) Adhesives in dentistry-Clinical considerations. Oper Dent 5:95-102.

37. Yap AUJ, Lim CC and Neo JCL (1995) Marginal sealing ability of three cervical restorative systems. Quint Int 26: 817-820.

38. Hilton T.J and Ferrancane JL (1998) Cavity preparation factors and microleakage of class II composite restorations filled at intraoral temperatures. Am J Dent 11: 123-130.

39. Estafan D, Dussetschleger FL, Mine LM and Kondamani J (2000) Class V lesions restored with flowable composite and added surface sealing resin. Gen Dent 48:78-80.

40. Bertolotti RL (1992) Conditioning of the dentine substrate. Oper Dent Suppl 5: 131-136.

41. Van Meerbeek B, Inokoshi S, Braem M, Lambrechts P, and Vanherle G (1992) Morphological aspects of the resin
- dentin interdiffusion zone with different dentin adhesive systems. J Dent Res 71: 1530-1540.

42. Perdigao J, Swift EJ, Denehy GE, Wefe JS and Donly KJ. (1994) In vitro bond strengths and SEM evaluation of dentin bonding systems to different dentin substrates. J Dent Res 73: 44-55.

43. Matos AB, Palma RG, Cintia Helena Coury Saraceni CHC and Matson E (1997) Effects of Acid Etching on Dentin Surface: SEM Morphological Study. Braz Dent J 8(1): 35 41.

44. Gateva N, Gusyiska A, Pavel Stanimirov P, Kabaktchieva $\mathrm{R}$ (2016) Effect of etching time and acid concentration on micromorphological change in dentin of both dentitions. J IMAB 22(2):1099-1110.

45. Hedayatollahnajafi S, Staninec M, Watanabl, L, Lee C, Fried D (2009) Dentin bond strength after ablation using a $\mathrm{CO}^{2}$ laser operating at high pulse repetition rates. Proc SPIE Int Soc Opt Eng 18; 7162: 71620F.

46. AbdullJabbar, Hasanin A and Barakat MD (1993) Shear bond strength of composite resin to acid and laser etched tooth structure. ADJ 8(2):281-287.

47. De Munck J, Van Meerbeek B, Yudhira R and Lambrechts P, Vanherle G (2002) Micro-tensile bond strength of two adhesives to Erbium:YAG-lased vs. bur-cut enamel and dentin. Eur J Oral Sci 110(4): 322-9.

48. Staninec M, Meshkin N, Manesh SK, Ritchie RO \& Fried D (2009) Weakening of dentin from cracks resulting from laser irradiation. Dent Mater 25, 520-52.

49. Moretto SG, Azambuja Jr, N, Arana-Chavez VE, Reis AF, Giannini M, Eduardo Cde P \& De Freitas PM (2011) Effects of ultramorphological changes on adhesion to lased dentin-Scanning electron microscopy and transmission electron microscopy analysis. Microsc Res Tech 74, 720-726.

50. Groth, EB, Mercer CE and Anderson P (2001) Microtomographic analysis of subsurface enamel and dentine following Er:YAG laser and acid etching. Eur J Prosthodont Rest Dent 9(2): 73-9 